\title{
Other interesting effects of alveolar corticotomies in orthodontics apart from the acceleration of tooth movement
}

T. Gellee', E. Ouadi'2, A.-L. Ejeili, ${ }^{3,4}$ N. Moreau ${ }^{3,4}$

1 Internal DESCO, Department of Oral Medicine, Bretonneau Hospital, AP-HP, Paris

2 AHU in ODF, Department of Oral Medicine, Bretonneau Hospital, AP-HP, Paris

${ }^{3} \mathrm{MCU}-\mathrm{PH}$ in Oral Medicine and Oral Surgery, Department of Oral Medicine, Bretonneau Hospital, AP-HP, Paris

4 Faculty of Dental Surgery, Paris Descartes University, Montrouge

\section{ABSTRACT}

The acceleration of orthodontic tooth movement due to alveolar corticotomies has been well documented in the literature. It is defined by a phenomenon of transient osteopenia named "the regional acceleratory phenomenon" by Frost. This biological mechanism has been described in studies on both humans and animals. However, other interesting effects in orthodontics are associated with alveolar corticotomies: higher amplitude of tooth movements, a decrease of the root resorptions and an increase of stability after orthodontic treatment.

\section{KEY WORDS}

Corticotomy, osteotomy, orthodontics

\section{INTRODUCTION}

The indications for orthodontic treatments in adults are constantly increasing. These treatments make it possible to correct-both functionally and esthetically-dentofacial harmony. Such orthodontic treatments often require long durations, and pose the risk of more serious complications at the dentoperiodontal level (increased risk of root resorptions and periodontal recessions are a risk of orthodontic treatment).

Various techniques for accelerating orthodontic dental displacement have been proposed to overcome this problem of

Address for correspondence:

Nathan Moreau

Faculty of Dental Surgery - Paris Descartes University, Montrouge - France

E-mail: nathan.moreau@parisdescartes.fr

This is an Open Access article distributed under the terms of the Creative Commons Attribution License (http://creativecommons.org/licenses/by/4.0), which permits unrestricted use, distribution, and reproduction in any medium, provided the original work is properly cited. 
treatment duration in adults, in particular the use of alveolar corticotomies.

An alveolar corticotomy can be defined as a controlled surgical lesion of the alveolar bone to induce a localized acceleration of bone remodeling, resulting in transient osteopenia and the facilitation of dental displacement at this level. As its name indicates, it only concerns the cortical bone and does not affect the medullary cavity unlike osteotomies, which involves both the cortex and medulla ${ }^{16}$.

Historically, Heinrich Köle (1959) was one of the first to propose a mechanistic hypothesis by proposing the concept of acceleration of the tooth movement by displacing "bone blocks." According to him, the cortical bone is one of the main factors preventing dental movement. By weakening this bone, he suggested that the speed of the dental movement could be accelerated. His surgical protocol included vestibular and lingual inter-radicular corticotomies as well as supra-apical osteotomies, creating removable bone blocks interconnected by the medullary cavity. The crowns of the teeth to be moved were then used as anchors to mobilize these blocks. Although this technique was effective in accelerating orthodontic treatment, severe complications such as pulpal necrosis were observed $^{12}$

Since then, various authors have supported this theory while making improvements to the initial operating protocol. In 1975, Düker improved the prognosis by sparing the crestal bone in his corticotomies ${ }^{8}$. In 1991, Suya replaced supra-apical osteotomy with a simple corticotomy; reporting fewer complications than Köle (root resorptions, pulpal necrosis, recurrence) ${ }^{21}$.
Currently, the consensual theory justifying accelerated tooth movement has been proposed by Wilcko et al. (2001), who radiographically assessed the presence of transient demineralization followed by remineralization at the corticotomy level. ${ }^{22}$ This phenomenon of transient local osteopenia was initially described on long bones by Frost and called "regional acceleratory phenomenon"10. They then proceeded to demonstrate that these zones of demineralization consists of collagenous tissues moving with the dental roots and remineralizing once the dental movement stopped. This theory is known as bone matrix transport."

The acceleration of the speed of orthodontic dental displacement by alveolar corticotomies has been extensively described in the literature and has in particular been the subject of controlled prospective studies with a high degree of scientific robustness. This surgical technique would allow, depending on the case, a 3-4-fold reduction in the duration of orthodontic treatment in adults. ${ }^{22}$.

However, alveolar corticotomies have other uses in orthodontic practice than the simple acceleration of dental displacement, which many orthodontists are unaware of. The alveolar corticotomies are particularly interesting in the increase of the envelope of the possible dental movements, in the reduction of the risk of root resorption and in the increase of the orthodontic post-treatment stability.

This article aims to take stock of the biological mechanisms underlying the effect of alveolar corticotomies and their consequences on these three less well-known indications of this surgical technique. 


\section{BIOLOGICAL MECHANISMS OF ALVEOLAR CORTICOTOMIES}

The regional acceleratory phenomenon (RAP), initially described in long bones by Frost in 1983, corresponds to rapid bone remodeling in response to surgical trauma such as a fracture, arthrodesis, osteotomy, or bone grafting ${ }^{10}$. It consists of an increase in osteoclastic bone activity (increased cellular turnover and decrease in regional bone density), followed by a state of transient osteopenia, which is then followed by complete bone healing with a return to initial bone density (increased osteoblastic activity). RAP starts a few days after the fracture with a peak at 1-2 months and may persist for 6-24 months ${ }^{22}$. This phenomenon allows an accelerated physiological bone healing at 2-10 times the normal speed.

In addition to the long bones, this phenomenon also affects the jaw bones. In 1994, Yaffe et al. showed an acceleration of bone growth after the retraction of a mucoperiosteal mandibular flap in rats, with a return to the original bone density after 120 days ${ }^{25}$.

Various authors (Midgett 1981, Goldie 1984, Verna 2000) have shown-in animal models - that increased bone turnover and osteopenia had an effect on the response to orthodontic forces, resulting in significantly faster tooth movement.

Baloul et al., in 2011, studied the biological response during dental movements with and without alveolar corticotomy. Orthodontic dental displacement

\section{SURGICAL PROCEDURES (Fig. 1-5)}

Before any corticotomy can take place, a healthy periodontium is essential to ensure optimal healing. is based on the property of the alveolardental ligament to maintain a constant width (no movement of the ankylosed teeth and implants) as well as on the turnover of the alveolar bone. In the "orthodontic treatment + corticotomy" group, osteoclastic cells and markers as well as bone demineralization were significantly greater after 7 days compared than in the "just orthodontic treatment" group. The tooth movement was continuous until day 42 in the group with corticotomies whereas in the group without corticotomies, we observed the following sequence: acceleration from D7 to D14 and stagnation until D28 and movement similar between the two groups from D28 to D42. Moreover, the association of resorption and bone formation in the early postcorticotomy phases presents many arguments that corroborate the improvement of the dental movements in the early phases following this treatment ${ }^{2}$.

Several other studies report that RAP would induce greater tooth movement than conventional orthodontic treatment alone. In humans, Charrier et al. described that the overall duration of treatment had been cut in half ${ }^{4}$, whereas Wilcko et al in their studies observed an acceleration of three to four times the normal rate ${ }^{22}$. These results are concordant with those of Cho et al. in dogs (two times faster in the mandible and four times faster in the maxilla) ${ }^{5}$.

Preoperative planning makes it possible to indicate a treatment, to decide on the decortication scheme and 
decide on the operating protocol. Many different corticotomy procedures have been proposed in the literature, but the intensity of decortication and its proximity to the teeth in question seem to be the main factors of success ${ }^{23}$.

The literature seems to agree that recommending an antibiotic premedication before alveolar corticotomies is beneficial ${ }^{9,17}$.

Orthodontic arches should be placed at least 1 week before the alveolar corticotomy so that the arch could be shaped at the end of the procedure.

The alveolar corticotomies are classically performed under local anesthesia, although they can also be done under general anesthesia (during associated orthognathic surgery).

The main operating times are as follows:

- Intrasulcal distal incision (at least one tooth of the last corticotomy line ${ }^{24}$ ) and retraction of a mucoperiosteal flap beyond the dental apex so as not to damage the neurovascular bundle.

- The corticotomy features are usually monocortical and localized exclusively on the vestibular side. It is essential to preserve the

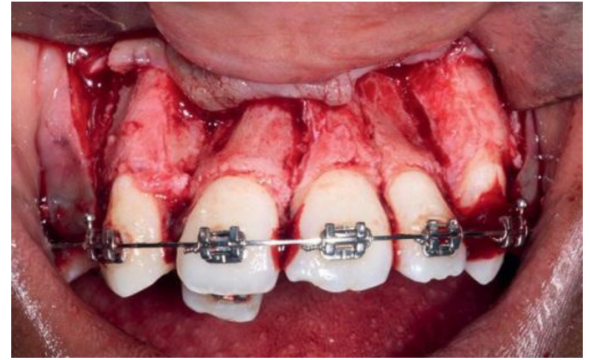

Figure 1

Alveolar corticotomy performed with a round bur for closing the anterior spaces.

alveolar rim to prevent the risk of periodontal recession, the vertical corticotomy is to be carried out 2-3 $\mathrm{mm}$ from the alveolar rim. ${ }^{8}$. These features of corticotomies are performed either with ball cutters, with a saw, or with a piezotome under abundant irrigation. In all cases, the bleeding of the operated area indicates a break in the medullary space (indicator of the good depth of the corticotomy) (Fig. 1). Most often, vertical cross-radicular corticotomies between the teeth in question are sufficient.

- The closure of the operative site is performed by $\mathrm{O}$-points or vertical padding with 5-0 absorbable or nonabsorbable thread.

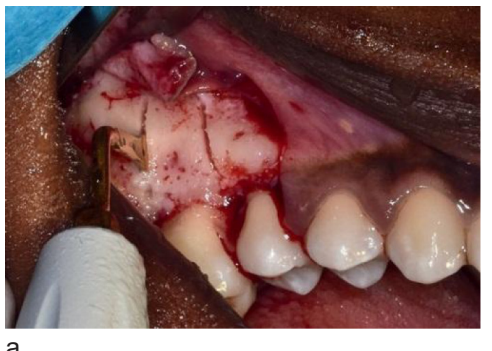

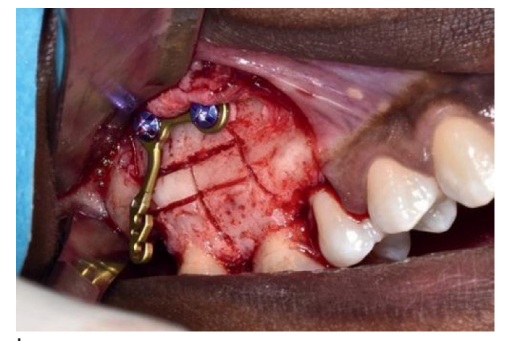

b

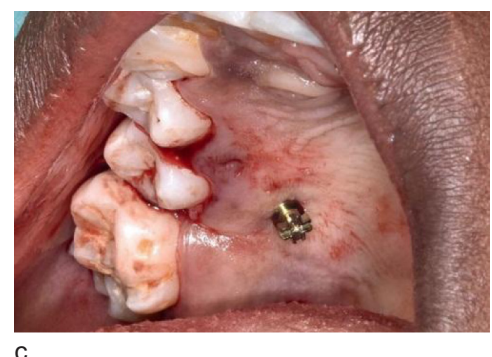

C

Figure 2

(a) Alveolar corticotomy performed by piezosurgery for intrusion of the molar. (b) Fitting of vestibular orthodontic traction plate. (c) Fitting of palatal orthodontic traction screws. 
Orthodontic activation should be done immediately after the corticotomy to maximize the acceleration of secondary dental movement by RAP.1,9. This RAP lasts 4-6 months, during which it is recommended to reactivate orthodontic traction every 15 days $^{18}$.

In order to limit any potential side effects (hematoma, edema, pain, discomfort) secondary to conventional

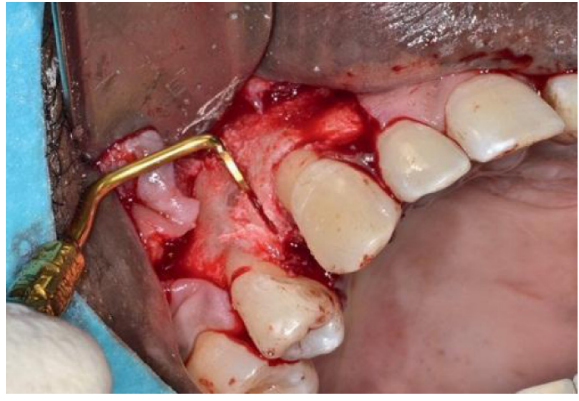

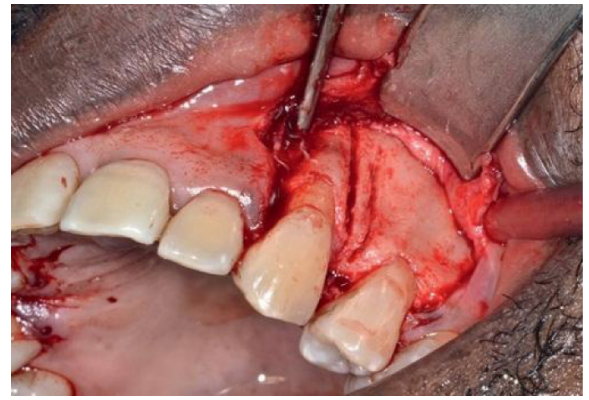

b

Figure 3

(a) Alveolar corticotomy performed by piezosurgery to close spaces in sector 1. (b) Alveolar corticotomy performed by piezosurgery to close spaces in sector 2.

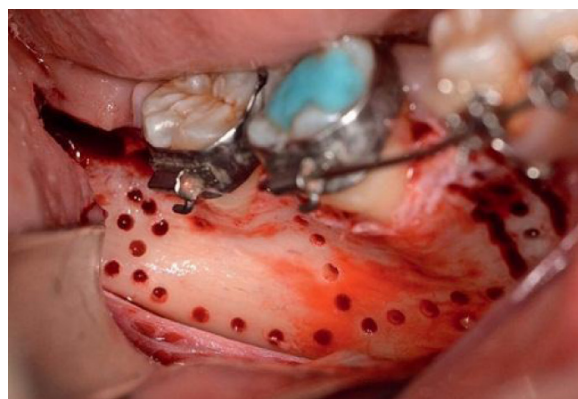

a

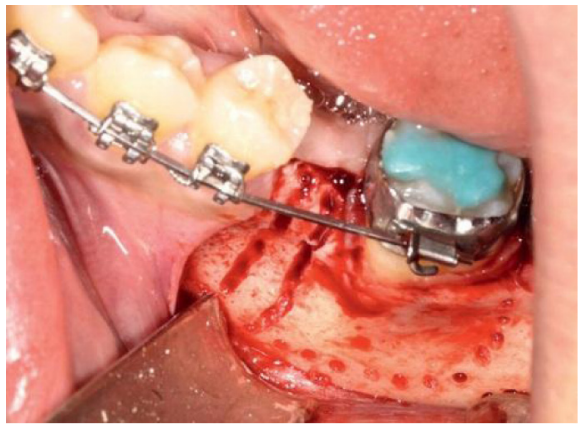

C

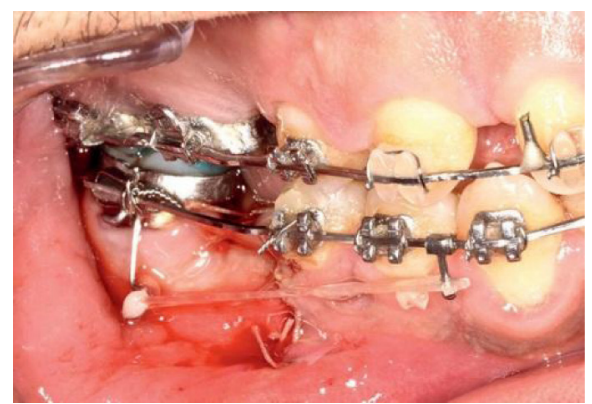

b

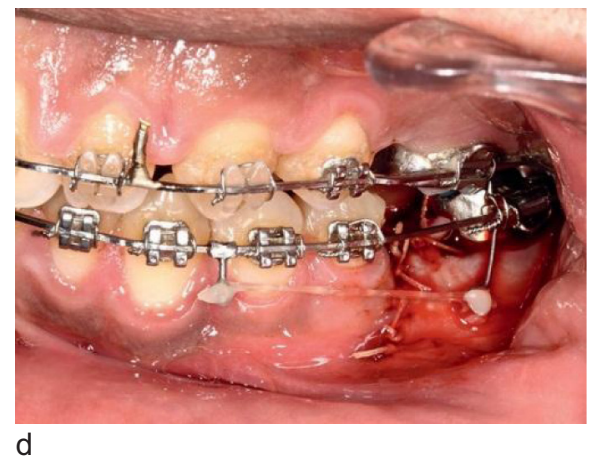

Figures 4

$(a, b)$ Intraoperative and postoperative view of alveolar corticotomy performed with a ball cutter for mesialization of molars in sector $4 .(c, d)$ Intraoperative and postoperative view of alveolar corticotomy performed with a ball cutter for mesialization of molars in sector 4. 

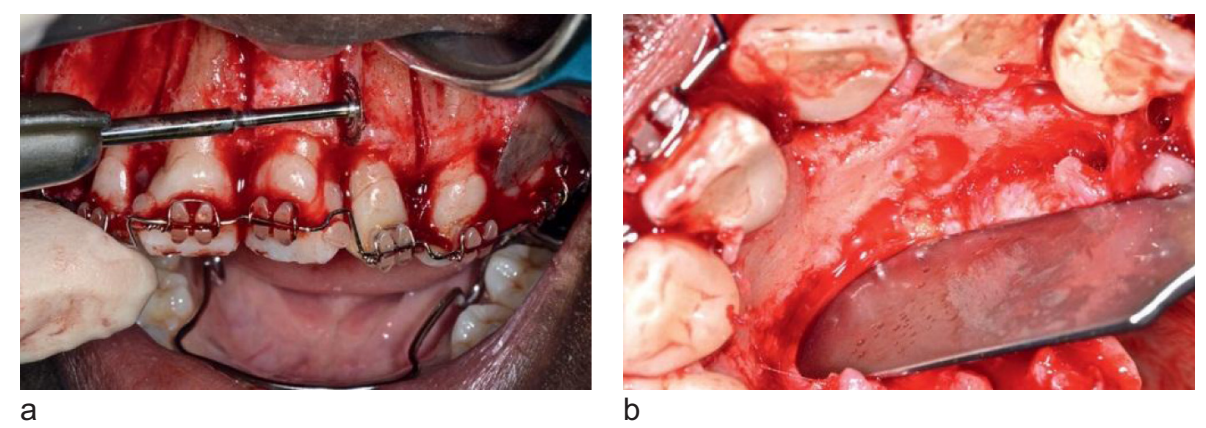

Figure 5

(a) Alveolar corticotomy performed on the diamond disc for space planning for the impacted canine. (b) Visualization of the impacted canine, corticotomy not performed on the canine.

Illustrations provided by doctors: Dr. Julie Leclercq, AHU Paris 7. Implantology. Pitié Salpêtrière Hospital Group - Dr. Rafael Toledo, PH Implantology Manager. Hospital group Pitié-Salpêtrière,

Paris

alveolar corticotomies, new mini-invasive approaches have been developed, which do not require a mucoperiosteal flap (Fig. 2a and 2b). However, these techniques could increase the risk of root damage during bone cutting. In order to compensate for this lack of visual control, cutting guides made by CAD/CAM have been proposed. ${ }^{3}$.

\section{"OVERLOOKED" INDICATIONS OF ALVEOLAR CORTICOTOMIES}

In addition to the well-known orthodontic movement accelerating effect, rapid bone remodeling induced by controlled surgical aggression of alveolar corticotomies provides other benefits in orthodontic practice, described below.

\section{Increasing the range of possible dental movements}

One of the lesser known effects of alveolar corticotomies is their impact on the range of possible tooth movements. In a 2007 original study in dogs, Lino et al. have studied the different effects of alveolar corticotomies on the mesialization of the third mandibular premolars, one side having benefited from alveolar corticotomy before being paired and the other being paired, serving as a control. Apart from an acceleration of tooth displacements, these authors also observed an increase in the range of these movements, twice as large compared to the unoperated side $^{11}$. These authors hypothesize that this increase in range could be, in fact, secondary to the acceleration of treatment (and that if the study had been 
continued longer, the premolar of the unoperated side could have moved as much as the operated side). Nevertheless, this team and others thereafter demonstrated increases in the magnitude of total tooth displacements in humans regardless of the speed of movement ${ }^{19}$. This increase in the magnitude of the dental displacements occurs in all three dimensions, opening up interesting perspectives in the management of transversal deficits (for details, read the bibliographical reference ${ }^{1}$ ).

\section{Decreased risk of root resorptions after orthodontic treatment}

During orthodontic dental displacement, the compression of the alveolar-dental ligament forms osteoclastic cells inducing bone demineralization as well as cell destruction (hyalinization) ${ }^{4}$. This hyalinization consists of a zone of aseptic necrosis having an acellular vitrified appearance, when viewed under a microscope (Reitan, 1951). It is the first phase of the tooth movement after the initial activation phase and persists for up to 4 weeks in children and 40 days in adults, explaining the delay observed before any dental movement. This hyaline zone is then resorbed (10-12 days) which leads to the creation of a new alveolodental ligament.

According to lino et al. (2007), the acceleration of postcorticotomy tooth movement is thought to be because of a considerable reduction in the phase of hyalinization during accelerated bone remodeling (explaining the differences in tooth movement kinetics between the operated and unoperated sides). The root resorptions occurring during the hyalinization phase, the alveolar corticotomies decreased their formation by decreasing the severity of this hyalinization phases. Therefore, in the same study, the authors found no radicular resorption on the corticotomy side compared with resorptions observed at 4 and 8 weeks on the treated side in a conventional way ${ }^{11}$.

In addition, by decreasing the total duration of orthodontic treatment, alveolar corticotomies also indirectly contribute to a reduction in the risk of root resorptions (risk proportional to the duration of orthodontic treatment).

\section{Increased stability after orthodontic treatment}

One of the major challenges of orthodontic treatment is to ensure and maintain post-treatment stability. Recurrence is frequent, especially for certain orthodontic movements (for example, rotations).

Because of rapid bone turnover, alveolar corticotomies can improve long-term orthodontic post-treatment stability by decreasing local "tissue memory." ${ }^{14,20}$. Nevertheless, immediate post-treatment orthodontic restraint remains necessary.

In addition, various authors have suggested the possibility of an increase in bone volume after alveolar corticotomies because of bone remodeling with greater osteoblastic activity than osteoclastic activity. 2,15,16,22. This postoperative increase in peridental bone volume would promote better post-treatment stability. 


\section{DISCUSSION}

Because of their multiple therapeutic effects and indications (for review, see $\left.^{16}\right)$, the alveolar corticotomies represent a very interesting adjuvant therapy in daily orthodontic practice.

The different effects generated by these alveolar corticotomies can only be fully optimized with the perfect collaboration between orthodontists and oral surgeons. The exchange between practitioners will allow the orthodontist and the oral surgeon to coordinate and take maximum advantage of the benefits of corticotomies and the various effects mentioned above. They will also discuss the best choice of decortication scheme ${ }^{13}$ and add dental avulsions or osteotomies to the protocol according to the clinical case and the desired orthodontic movements.

Moreover, in certain specific cases where the orthodontist is reluctant to choose orthognathic surgery, but orthodontic treatment alone is insufficient, alveolar corticotomies may be an interesting solution ${ }^{6,7}$ with less postoperative follow-up.

Although alveolar corticotomies were decried for a long time due to their side effects (pain, swelling, hematoma), corticosteroids are useful for controlling the side effects. Corticosteroids are generally well tolerated by patients, and complete recovery after alveolar corticotomy can be expected between 7-10 days, with less pain/discomfort than that in dental avulsions ${ }^{1}$. Their use in daily orthodontic practice is therefore perfectly justified and is part of an improvement in the quality of orthodontic treatments-especially in adults-accompanied by the best understanding of the biological mechanisms underlying orthodontic dental movement.

\section{CONCLUSION}

The addition of alveolar corticotomies during orthodontic treatment allows for a reduction in the duration of treatment, an effect well known to orthodontists. In addition to this effect which has been the subject of many scientific articles, it also allows larger tooth displacements, a reduction in the risk of root resorption and a gain in stability after the removal of orthodontic devices. Close collaboration between the orthodontist and the oral surgeon will make it possible to choose the optimal decortication protocol according to the indication while favoring a minimally invasive approach.

Conflict of interest: The authors declare no conflicts of interest.

\section{REFERENCES}

1. Al-Naoum F, Hajeer MY, Al-Jundi A. Does alveolar corticotomy accelerate orthodontic tooth movement when retracting upper canines? A split-mouth design randomized controlled trial. J Oral Maxillofac Surg 2014;72:1880-9. 
2. Baloul SS, Gerstenfeld LC, Morgan EF, Carvalho RS, Van Dyke TE, Kantarci A. Mechanism of action and morphologic changes in the alveolar bone in response to selective alveolar decortication-facilitated tooth movement. Am J Orthod Dentofacial Orthop 2011;139:S83101.

3. Cassetta M, Giansanti M. Accelerating orthodontic tooth movement: A new, minimally-invasive corticotomy technique using a 3D-printed surgical template. Med Oral Patol Oral Cir Bucal 2016:21(4):e483-487.

4. Charrier J-B, Bryon FB, Racy E, Steve M, Monteil J-P, Bobin S. Traitement orthodontique accéléré par corticotomies alvéolaires chirurgicales chez l'adulte. Int Orthod 2008;6:355373.

5. Cho K-W, Cho S-W, Oh C-O, Ryu Y-K, Ohshima H, Jung H-S. The effect of cortical activation on orthodontic tooth movement. Oral Dis 2007;13:314-19.

6. Choo H, Heo H-A, Yoon H-J, Chung K-R, Kim S-H. Treatment outcome analysis of speedy surgical orthodontics for adults with maxillary protrusion. Am J Orthod Dentofacial Orthop 2011;140:e251-262.

7. Chung K-R, Kim S-H, Lee B-S. Speedy surgical-orthodontic treatment with temporary anchorage devices as an alternative to orthognathic surgery. Am J Orthod Dentofacial Orthop 2009;135:787-98.

8. Düker J. Experimental animal research into segmen- tal alveolar movement after corticotomy. J Maxillofac Surg 1975;3:81-84.

9. Echchadi MEM. The role of alveolar corticotomies in orthodontic anchorage management. Int Orthod 2014;12:171-187.

10. Frost HM. The biology of fracture healing. An overview for clinicians. Part I. Clin Orthop 1989:283-293.

11. lino S, Sakoda S, Ito G, Nishimori T, Ikeda T, Miyawaki S. Acceleration of orthodontic tooth movement by alveolar corticotomy in the dog. Am J Orthod Dentofacial Orthop 2007;131:448.e1-448.e8.

12. Kole H. Surgical operations on the alveolar ridge to correct occlusal abnormalities. Oral Surg Oral Med Oral Pathol 1959;12(5):515-529 concl.

13. Kook YA, Lee W, Kim SH, Chung KR. Corticotomy-assisted space closure in adult patients with missing lower molars. J Clin Orthod JCO 2013;47:85-95; quiz 139.

14. Makki $\mathrm{L}$, et al. Mandibular irregularity index stability following alveolar corticotomy and grafting: A 10-year preliminary study. Angle Orthod 2015;85:743-9.

15. Moreau N, Charrier JB. Formation osseuse et cortico- tomies à visée de facilitation métabolique : existe-t-il une ostéogenèse induite par les corticotomies alvéolaires ? Orthod Fr 2015;86(1):113-120.

16. Moreau N, Charrier JB. EMC Médecine Buccale 2016;11(4):1-10. [Article 28-670-T-10]

17. Oliveira DD, de Oliveira BF, de Araújo Brito HH, de Souza MMG, Medeiros PJ. Selective alveolar corticotomy to intrude overerupted molars. Am J Orthod Dentofacial Orthop 2008;133:902-908.

18. Sebaoun JD, Surmenian J, Ferguson DJ, Dibart S. Accélération du mouvement dentaire orthodontique suite à une décortication alvéolaire sélective : justification biologique et résultat d'une technique novatrice d'ingénierie tissulaire. Int Orthod 2008;6(3): 235-249 n.d.

19. Sebaoun J-DM, Ferguson DJ, Wilcko MT, Wilcko WM. Corticotomie alvéolaire et traitements orthodontiques rapides. Orthod Fr 2007;78:217-225.

20. Sitbon M-C, Charrier J-B. Orthodontie accélérée par corticotomies alvéolaires : approche clinique et expérimentale. Rev Orthopédie Dento-Faciale 2009;43:189- 198. 
21. H. Suya. Corticotomy in orthodontics. Mech Biol Basics Orthod Ther Heidelb Ger Huthig Buch Verl 1991:207-26 n.d.

22. Wilcko WM, Wilcko T, Bouquot JE, Ferguson DJ. Rapid orthodontics with alveolar reshaping: two case reports of decrowding. Int J Periodontics Restorative Dent 2001;21:9-19.

23. Wilcko W, Wilcko MT. Accelerating tooth movement: The case for corticotomy-induced orthodontics. Am J Orthod Dentofacial Orthop 2013;144:4-12.

24. Wilcko MT, Wilcko WM, Pulver JJ, Bissada NF, Bouquot JE. Accelerated Osteogenic Orthodontics Technique: A 1-Stage Surgically Facilitated Rapid Orthodontic Technique With Alveolar Augmentation. J Oral Maxillofac Surg 2009;67:2149-2159.

25. Yaffe A, Fine N, Binderman I. Regional Accelerated Phenomenon in the Mandible Following Muco-periosteal Flap Surgery. J Periodontol 1994;65:79-83. 